\title{
An Overview of Practicability and Application of 300M Steel in the Face of Stress Corrosion Cracking Issue
}

\author{
T. N. Guma ${ }^{a *}$, E. O. Ajayi ${ }^{b}$, and M. H. Mohammed \\ a,b,c, Department of Mechanical Engineering Nigerian Defence Academy, Kaduna, Nigeria \\ a*Email: tnguma@nda.edu.ng
}

\section{Article Info}

Received 25July 2020

Revised O1August 2020

Accepted 03August 2020

Available online 31August 2020

Keywords:

Steel, Special, Applications, SCC, Alleviation, Methods, Pros \&Cons

Research, Improvement

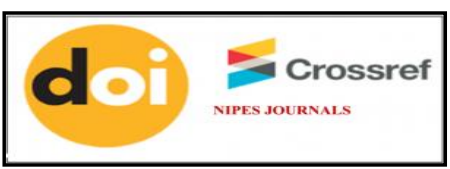

https://doi.org/10.37933/nipes/2.3.2020.24

https://nipesjournals.org.ng

(C) 2020 NIPES Pub. All rights reserved

\begin{abstract}
The paper highlights 300M steel as an engineering material that is commonly used in special applications where fracture toughness, ductility, and ultra-high strength in the 2000-2070MPa range is required such as aircraft landing gear, airframe parts, undercarriage components, gears, shafts, and bolts. Stress corrosion cracking (SCC) is recapitulated as the drawback of the steel in its service applications. The aim of the paper is to call attention to the SCC problem and highlight the pros and cons of the existing alleviation methods for better appreciation of the way forward. The overview indicates interminable positive research inputs in alleviating SCC of the steel in its service applications by; use of coatings, heat and surface-treatments, inducement of surface compressive stresses, design techniques, and cathodic protection. It is however seen that SCC alleviation of the steel has not yet reached ideal level due to some impracticability and cost implications in using the SCC control methods in many cases, and no better alternative material has been found for the steel. Only few research inputs on the numerous environmental types that the steel can be in service contact with are found in the literatures for its SCC alleviation. Improving practicability and versatility of the existing SCC alleviation methods and optimization of SCC-susceptibility test information of the steel from much larger number of the environmental types and their various levels of combinations are deemed needful towards ideal SCC alleviation of the steel
\end{abstract}

\section{Introduction}

Corrosion is an inevitable natural phenomenon that destructively attacks a material especially metal by either chemical or electrochemical reaction between the material and its environment $[1,2]$. Material corrosion can occur in any environment other than a vacuum and results in serious obstacle to economic and industrial advancements and safety depending on its extent and how it has been controlled. The consequences of corrosion are manifold and the implications of these consequences on the safety, reliability and efficiency of operation of engineering equipment or systems are often much far-reaching than the simple mass loss of metals. Various kinds of corrosion failures of engineering systems or structural components can occur in their service applications, and the need for their expensive replacement may arise even though the amount of material destroyed by corrosion is quite small [3]. 
Different forms and types of corrosion are encountered in engineering use of materials but one type that is much detested is stress corrosion cracking (SCC) [4, 5]. SCC can result in material failure with disastrous consequences. It can occur by exposure of the material to corrosive environment while under sustained tensile stress. SCC occurs by formation and growth of cracks on a material while under the tensile stress in the corrosive environment often at temperatures well above ambient values. It is the result of a combination of three factors; a susceptible material, exposure to a corrosive environment, and tensile stresses above a threshold. If any one of these factors is eliminated, SCC initiation becomes impossible [5, 6]. Material failure by SCC is most often rapid and unpredictable and can occur in a short time within few hours or take years and decades to occur after the material is applied in service. SCC is known to be more associated metallic alloys, ceramics, polymers, concretes, and glass other than pure materials. Most alloys are more liable to SCC in some environmental types than others, so SCC prevention or alleviation requires careful environmental type consideration in the design of specific alloy type for service application $[5,6]$. The stress that causes SCC of a metallic alloy can be much lower than its material yield strength, and the environment that causes SCC of the alloy is often the one which is only mildly corrosive to it. Hence, metallic parts with severe SCC can appear bright and shiny, while being filled with microscopic cracks. The specific environment is therefore of crucial importance in SCC study, since even very small concentrations of certain highly active chemicals are needed to produce catastrophic cracking, often with unexpected and devastating failure [6,7]. There are a number of approaches that can be used to prevent or at least alleviate SCC. In an ideal world; SCC prevention or alleviation strategy starts operating at the design stage and focuses on material selection, the stress limitation, and control of the environment. The skill of the engineer then lies in selecting the strategy that delivers the required performance at minimum cost $[3,5]$.

$300 \mathrm{M}$ steel is an ultra-high strength low-alloy vacuum melted steel that is engineered with chemical element specifications of $0.38-0.46 \%$ carbon, $0.7-0.95 \%$ chromium, $0.6-0.9 \%$ manganese, $0.3-$ $0.65 \%$ molybdenum, $1.65-2 \%$ Nickel, $0.01 \%$ maximum phosphorus, $1.45-1.8 \%$ silicon, $0.01 \%$ maximum sulfur, $0.05 \%$ minimum vanadium, and iron the balance by composition [7]. It is essentially, a modified AISI 4340 steel with silicon, vanadium, and slightly greater carbon and molybdenum contents than the AISI 4340 steel. It is often used in applications that require fracture toughness, ductility, and strength in the 2000-2070MPa range such as; aircraft landing gear, airframe parts, undercarriage components, gears, shafts, and high strength bolts. Unfortunately, $300 \mathrm{M}$ steel like all ultra-high strength steels is vulnerable to SCC and corrosion fatigue which can lead to devastating catastrophic failure consequences especially for aircraft landing gear [7, 8, 9]. Because of the corrosion behavior of $300 \mathrm{M}$ steel as an important engineering material, a number of researches have been conducted in the last few decades to improve its corrosion resistance with respect to SCC susceptibility in a number of environments or find alternative better materials for it but the ideal level is yet to be reached [8,9]. Specifications of 300M steel is covered by the UNS K44220, ASTM A646 (300M-8), ASTM A579 (32), AMS 6417, AMS 6419, MIL S-8844 (3), MIL S-8844 Class 2 sp [8, 9].

The aim of this paper is to call attention to the SCC drawback of 300M steel and highlight the pros and cons of the existing applicable methods of alleviating the problem, and technological efforts achieved; for better appreciation of the way forward by concerned engineers and researchers. 


\section{Environmental Consideration in SCC Alleviations of 300M Steel}

All methodical approaches for preventing or alleviating SCC of $300 \mathrm{M}$ steel require sound knowledge of the nature and corrosivity extents of various types and combination of environments the material can be in contact with during its service applications [10]. As an aviation material, this type of steel is more commonly exposed in service to atmospheric environment. It can also be applied in someservice environments at much higher temperatures than atmospheric environment such as components in boilers or engines; and in water environment in the form of ship components such as shafts, bolts, gears, and anchoring chains [7]. Atmospheric and water environments are complex in composition with unpredictable corrosivity levels that vary from time to time and location to location around the globe. The common variable corrosive species or agents in these environments which can influence SCC of different metals to various degrees are :temperature differences, carbon dioxide, sulfur compounds, hydrogen, sulfides, oxygen, water, chlorides, $\mathrm{Ph}$, nitrates, sulfates, $\mathrm{NO}_{\mathrm{X}}$ gases, micro-organisms, air or water flow rates with impingement forces, and pressure differences. All these variables and many more and their synergistic effects can influence atmospheric or water environmental corrosivities to abnormally high levels at many locations around the globe. Such corrosivity levels can be quite deleterious to many types of materials thereat including $300 \mathrm{M}$ steel [10]. It is therefore imperative not to base any material SCC prevention or alleviation method on the average environmental corrosivity and condition around the globe. Ideally, the method should be based on the specific environmental corrosivity for every type of metal or optimal global environmental corrosivity level and condition for structural parts of systems like aircrafts which are subjected to frequent location changes around the world. It is thus evident that reliable optimal global environmental corrosivity level and environmental condition for SCC alleviation of $300 \mathrm{M}$ steel is needful for some applications such as aircraft components.

\section{Applicable Methods of Alleviating SCC of 300M Steel}

The main existing applicable methods of alleviating SCC of 300M steel are by design, use of coatings, heat and surface treatments, control of residual tensile and compressive stresses, minimization of operating temperature, use of suitable corrosion inhibitors, environmental modification, periodic corrosion monitoring and inspection, use of alternative better material, cathodic protection, and positive research inputs for advancing the use of all these methods [3, 11].

\subsection{Design method}

Design techniques can be used to alleviate SCC of 300M steel by limiting the operative stress levels in the steel structural components to safe levels. Prevention or alleviation of the SCC in various service environment has to begin at the design stage of the steel components or structural system by avoiding faulty geometrical design features that promote corrosion and using correct factors of safety that cater for all stresses that can cause SCC of the steel which can be much lower than the tensile strength of the steel. Observance of some design details for the sake of SCC protection of the steel will involve little or no increase in the cost of a structural system and will result in substantially decreased maintenance cost [3]. However, the method has some demerits because [3]: i. It may not be feasible or economical for some practical situations; and in most cases, it can only reduce the chance of SCC occurring but not prevent it completely.

ii. Designing the steel structural components for the purpose SCC or other types of corrosion control may have serious effects on system performance that are not related to corrosion per se and incur extra cost from the design. 
iii. Very often the effects of corrosion cannot be clarified at the early stage of design because information is lacking either on the precise environmental SCC threshold stresses and other conditions or behavior of material in a certain configuration or application under these conditions.

\subsection{Coating methods}

Coating protection can be used to prevent SCC of 300M steel by isolating corrosive environmental chemical species from contacting the steel in its service applications. The use of coatings, particularly paints and organic coatings is the most available, versatile, widely used and economical method that can be exploited for protecting most forms of steel corrosion including SCC. About $90 \%$ of all steel surfaces are protected by paints or organic coatings. The coating method however has some drawbacks because not all types of coatings can be effective on the steel in every type of environment or have the same protective life. Evaluation of existing different types of coatings or formulation of new coatings for durable effective SCC corrosion protection of the steel in its entire service environmental types requires great skills and costly researches. Coatings can easily fail any time in service by unknown causes and expose the steel surface to the environmental corrosion that can result into unpredictable SCC. Therefore, the reliability of even effective coatings for SCC protection requires frequent inspections and monitoring and timely maintenances or renewals of the protection with costs $[3,12]$.

\subsection{Heat and surface treatments}

Heat treatment can be used to alleviate SCC of 300M steel by controlling its hardness and wear resistance to better levels. Heat treatment is advantageous because it in-builds SCC control in the steel structural components to make them less prone to corrosion inspections and maintenance in service where accessibility can be very difficult for other protective methods like coating, cathodic protection, and use of inhibitive treatments. It can also be used per se to improve corrosion resistance of the steel in applications where the other protective methods are not feasible and it can be used to supplement these methods in customized needs for greater corrosion protection. The method however has some demerits. It is more costly, time-consuming, and laborious method for mass corrosion control of structural steel works compared to most other protective methods such as organic coatings, cathodic protection, and inhibitive treatment. Moreover, it can improve corrosion resistance but not eliminate corrosion of material [13].

\subsection{Control of residual tensile and compressive stresses}

SCC of fabricated 300M steel structural components can be alleviated by removing residual tensile stresses in the components which are usually not quantitatively known in values and can negatively affect the designed operative stress levels of the steel components to unpredictable and unsafe values. The residual stresses can be removed by thermal treatments such as annealing and normalizing and; non-thermal processes such as shot peening, and laser peening. The steel components can also be alleviated from SCC by inducing surface compressive stresses into the components to raise the designed service stress level of the components to some safe higher level by using various surface treatment processes such as shot peening, laser peening, and high frequency impact treatment for weld toes. Although control of residual tensile and compressive stresses can appreciably improve SCC resistance of the steel, the method can be attended with appreciable cost especially in many applications that involve massive components and mass SCC alleviation of steel components. The reliability level of the method may not be quantitatively ascertained, so the safe stress levels within which the components are to be operated in service can be exceeded and SCC can still occur $[5,14]$. 


\subsection{Minimization of operating temperature}

Studies have indicated that the susceptibility of steel material to SCC increases with its environmental temperature. By this, it understandable that SCC of 300M steel can be alleviated by minimizing the temperature of its service environment to reduce corrosion rate and strength deterioration of the steel parts. The method is seen to have some disadvantages: It can require costly cooling facilities to reduce environmental temperature. Cooling to reduce environmental temperature may result in un-envisaged operational problems in service application of the material that are not related to corrosion per se. The method can be feasible only in confined environments such as engines and boilers but not open atmospheric space, and vast water and soil environments [15].

\subsection{Use of suitable corrosion inhibitors}

Suitable corrosion inhibitors can be used to alleviate SCC of $300 \mathrm{M}$ steel by negating the service environmental corrosivity to the steel. Use of corrosion inhibitors is the most feasible and economical method of alleviating steel corrosion in recirculation systems and some other confined aqueous environments. Most inhibitors in existence are cheap, abundant; and their application is easy and fast, once the right application conditions are established. However, the method has many shortcomings [3, 11]. For example [3, 11]:

i. It is not applicable to protection of the steel in the atmospheric environment, and not all inhibitors are suitable for all other environments.

ii. The lives of inhibitors vary from hours to days, months and years depending on the type, and type of environment. It could therefore require costly tests in an environment with a particular inhibitor for some time, before a design concentration of the inhibitor for the environment is made. The use suitable inhibitors for SCC protection of $300 \mathrm{M}$ steel requires meticulous costly researches on the various types of existing inhibitors or potential ones to establish the right conditions for applying them

iii. For effectiveness of corrosion inhibition, use of corrosion inhibitors is applicable only where chemical and conditions monitoring is feasible. All corrosion inhibitors have a $\mathrm{pH}$ range in which they are effective, so close Ph control is often necessary to ensure continued efficiency of the inhibitive treatments. To be fully effective, corrosion inhibitors require to be present above a certain minimum concentration, otherwise corrosion that can occur with insufficient inhibitor may be more severe than the complete absence of inhibitor. Effective inhibitor application is affected by the liquid composition such as; oil and the water composition ratio, the types of oil and the water composition. Other factors that affect the application include fluid velocity, type of geological formation, solubility and specific gravity of the inhibitor to be used, smoothness of the materials to be protected, and the prevailing temperature. This generally makes inhibitor application difficult or complex for many practical situations.

iv. Effective protection by corrosion inhibitor relies on the continued access of the inhibitor to all parts of the steel surfaces. Where this condition is difficult to achieve due to presence of crevices at some points, dead-ends in pipes, gas pockets., deposit of corrosion products, etc, SCC can occur at these sites even though the rest of the steel structural system remains adequately protected.

\subsection{Environmental modification}

Environmental modification can be used to alleviate SCC of $300 \mathrm{M}$ steel by removing known corrosive constituents of the environment such as oxygen, chlorides, acidity, moisture, and carbon dioxide which can make the steel susceptible to SCC. For example, the environment can be 
modified by de-aeration, dehumidification, neutralization, de-chlorination, de-oxygenation, etc. One limitation of this method is that it is only feasible in closed environments but not open environments like the atmosphere or vast water and soil environments because of infeasibility and much input requirements with cost. It will also require chemical composition analysis of the environment to know the corrosive species therein to be removed $[3,11]$.

\subsection{Periodic corrosion monitoring and inspection}

Periodic corrosion monitoring and inspection can be used to prevent or alleviate SCC of 300M steel by corrosion rate measurements performed under practical operating conditions of the steel structural components to acquire data on the rate of deterioration of the components for their maintenance purpose. Periodic corrosion inspection can be used to supplement corrosion monitoring to alleviate SCC of the steel components by using gained insight into the amount and severity of damage done to the steel components for better maintenance of the components [3]. However, the methods have the following shortcomings [3]:

i. Information from corrosion monitoring and inspection is most accurate and effective only when monitoring uniform or nearly uniform corrosion and least effective and accurate in monitoring mechanical phenomena, pitting or localized corrosion, stress corrosion cracking, thermal effects, etc.

ii. Most of the techniques used in corrosion monitoring are more reliable and applicable to confined environments where the monitored variables do not change appreciably.

iii. For a large part, structure, or system; whose corrosion rates are different at different locations on it, applying corrosion monitoring or inspection to obtain reliable results becomes more tedious.

\subsection{Use of alternative better materials}

The lists of suitable materials for various types of environments are documented by some reputable national and international organizations such as, ISO, ASTM, NACE, and ANSI which can be consulted to make selections. Availability and cost-justification of any suitable alternative material to $300 \mathrm{M}$ should ultimately dictate its selection. Alternative material selection for the steel will also require the use of metal corrosion resistance and properties data in combination with information on environmental conditions to choose the material that resists SCC better than the steel in all its service environments. At present, no better substitute material has been found for 300M steel [3].

\subsection{Cathodic protection}

Cathodic protection can be used to prevent or alleviate SCC of $300 \mathrm{M}$ steel structures that are immersed or imbedded in aqueous environments by impressing a counter corrosion current on the metal in a sufficient amount to neutralize corrosion current, or making the structures cathodes. Cathodic protection is economical, durable, and more reliable than most of the other protective methods. If properly implemented and maintained corrosion is impossible from cathodic protection. However, cathodic protection is applicable only in aqueous electrolyte or some damp soil environments. It cannot be applied in controlling atmospheric SCC of the steel, since it is not feasible to immerse an anode in thin condensed film of moisture or droplets of rain in the atmosphere to protect the steel [3].

\subsection{Continued use of positive research inputs}

As excellent as the foregoing discussed SCC alleviation methods are, it is obvious that all of them have demerits. Many of the methods are impracticable in many cases and even where they methods are feasible it is demonstrable that the cost can be quite high. It can therefore be appreciated that; it is impracticable and/or not cost-justifiable to use most of the methods for reliable SCC alleviation 
of the steel in every circumstance of its service environments. By this, it means that the material can still fail in service application with the attendant consequences. Literature survey shows that there have been continued research efforts in industry, military, and academia to improve the SCC alleviation methods or develop new ones. There have also been continued research efforts to know SCC susceptibility levels of $300 \mathrm{M}$ steel in the multifarious corrosive environments it can be in associated service contact with, to establish requisite threshold stresses for use in its SCC alleviation methods. Some of such research efforts are presented as follows:

John Pechonick [16] investigated the effect of cathodic protection on the stress corrosion characteristics of 300M low alloy steel. The objective of his investigation was to determine if stress corrosion failure of $300 \mathrm{M}$ steel is accelerated by the application of cathodic protection. He conducted the testing on notch tensile specimens that were coated with vacuum cadmium, electroplated cadmium, and vacuum aluminum. All his specimens were stressed and placed in an aqueous sodium chloride environment. He monitored and drew graphs of the failure times for the specimens that characterized the stress corrosion resistance of $300 \mathrm{M}$ steel and the cathodic protection systems. He used fractography techniques to study the failure surfaces to determine the type of failure mechanism. The results of his research indicated that:

i. The hydrogen evolved during cathodic protection of $300 \mathrm{M}$ steel by vacuum aluminum and vacuum cadmium and embrittled the steel and accelerated failure.

ii. The cathodic protection afforded by vacuum cadmium accelerated stress corrosion failure of $300 \mathrm{M}$ steel at all stress levels and significantly below $60 \%$ of ultimate tensile stress of the steel.

iii. The vacuum aluminum did not afford adequate protection to $300 \mathrm{M}$ steel so premature failure could be expected at all stress levels from the protection.

iv. The electroplated cadmium afforded excellent cathodic protection to $300 \mathrm{M}$ steel and did not accelerate failure.

v. A notch through the cathodic coating to the base steel did not increase the failure susceptibility of $300 \mathrm{M}$ steel.

The effect of temperature on stress corrosion cracking of high-carbon $300 \mathrm{M}$ steel in deionized water was investigated by Ryder and Pickel [17]. They conducted tests with wedge-opening-load specimens at 0,23 , and $90^{\circ} \mathrm{C}$. They found that stress corrosion crack growth rates above the SCC threshold $\left(K_{\text {Iscc }}\right)$ increased with increasing temperature to essentially constant rate at each temperature. They also found that crack growth rates appeared to be described by an Arrhenius-type rate expression. Lastly, they showed by the tests that apparent SCC threshold stress $\left(K_{\text {Iscc }}\right)$ of the steel at $23^{\circ} \mathrm{C}$ was approximately $12.1 \mathrm{MPa}$, and at $90^{\circ} \mathrm{C} 16.5 \mathrm{MPa}$, but at $0^{\circ} \mathrm{C} ; K_{\text {Iscc }}$ appeared to be lower than at $23^{\circ} \mathrm{C}$.

The resistance of $300 \mathrm{M}$ steel to $\mathrm{SCC}$ in a $3.5 \% \mathrm{NaCl}$ solution was studied as a function of heat treatment by Padmanbhan and Wood [18]. They found that the test threshold stress intensity of the steel was affected by micro-structural features, including; prior austenite grain size, amounts of retained austenite, and twins, in addition to grain boundary segregation and fracture toughness of the steel. They also found that crack growth rate was dependent on microstructure and segregation, but the number of constraint points exerted the maximum influence. They also studied effect of a modified heat treatment, which had been shown to improve all investigated mechanical properties to a significant extent on SCC properties. They discussed the results in terms of microstructure and fractography and found that this heat treatment resulted in significantly higher threshold stress intensity and lower crack growth rate.

Effects of variations in microstructure and strength on the SCC susceptibility of three medium to high strength steels namely; H13, 300M, and HY-130, in 3.5\% $\mathrm{NaCl}$ were systematically studied by Kerr et al [19]. They found that superimposed on the expected inverse dependence of KISCC on yield strength was more than an order of magnitude reduction in crack growth rate, with no strength penalty. They analyzed these results in terms of the possible relative roles of different micro- 
structural features, in particular retained austenite; whose detailed behavior was the subject of a companion paper.

Kozol and Neu [20] pointed out that in low alloy steels of about $0.40 \%$ carbon and greater, such as $300 \mathrm{M}$ steel, the martensite formed is plate type, exhibiting a twinned substructure; and the toughness is low compared to steels with lathe type martensite. They also hinted that toughness, crack initiation and crack growth rate can be affected by the presence of various types and sizes of alloy carbides in the microstructure and coarse carbides are visible in the $300 \mathrm{M}$ microstructure, at a magnification of 1000. Their work also showed that there was a significant reduction in toughness for this steel, as compared to the fine microstructure of the low carbon martensitic steels; and the presence of coarse carbides may provide sites for crack initiation and result in increased susceptibility to SCC. Lee and Waldman [21] noted that carrier-based aircraft landing gear demands a tough, corrosionresistant material. They recognized the acceptance of $300 \mathrm{M}$ steel as the standard material for landing gear because of its high tensile strength but lamented its low corrosion resistance and fracture toughness and considered it ill-suited for advanced aircraft landing gear. They also noted that a newly developed nickel-cobalt alloy steel, named "AerMet 100" had an outstanding combination of high fracture toughness and high tensile strength. Since its mechanical properties surpass those of the $300 \mathrm{M}$ steel. They opined that the steel has great potential for application to aircraft landing gear and other fracture critical components but also lamented that its corrosion behavior was not fully understood. They therefore initiated a study to characterize the corrosion behavior of the AerMet 100 steel. Their characterization effort included clarification of stress corrosion cracking, immersion corrosion, salt spray corrosion, and humidity corrosion of the steel. For comparison, they concurrently performed an identical study for $300 \mathrm{M}$ steel. Their results indicated that AerMet 100 steel is superior to $300 \mathrm{M}$ steel with respect to corrosion resistance as well as mechanical properties. Hiten Awasthi [22] conducted a study with the aim to model the behavior of residual stresses in shot-peened 300M landing gear steel affected by heat treatment with the understanding that residual stresses can have a significant influence on the mechanical behavior of major components under stresses, and information regarding the stability of existing residual stress states is of significant importance in service performance of the steel. In his experiment, he paid special attention to consequences of the heat treatment processes on compressive residual stresses induced in material by shot peening. He investigated the relaxation in residual stress due to addition of thermal energy by heat treatment at different temperatures and times. He used an existing model to create a stress relaxation equation for the high-strength $300 \mathrm{M}$ steel. He also examined the effect of heat treatment on residual stress distribution at subsurface level. He focused his study on the initial compressive residual stress field produced by common aerospace peening conditions and by how much isothermal exposure alters this stress and factors affecting the stress relaxation as well as fatigue life of the affected components.

Prevéy and Jayaraman [9] conducted a study with the aim of mitigating SCC and corrosion fatigue failures in $300 \mathrm{M}$ landing gear steel using mechanical suppression. They reaffirmed that $300 \mathrm{M}$ steel is widely used in landing gear because of its unique combination of ultrahigh strength with high fracture toughness. They however lamented that $300 \mathrm{M}$ is vulnerable to both corrosion fatigue and SCC failures with catastrophic consequences for aircraft landing gear. They noted that plating and shot peening surface treatments currently used to extend life of the landing gear are only partly effective. They also noted that a surface treatment is needful for mitigation of foreign object damage (FOD), SCC, and corrosion fatigue. In their study, they described the use of low plasticity burnishing (LPB) to mechanically suppress stress sensitive corrosion failure mechanisms of the steel in $3.5 \%$ salt solution. They compared the fatigue and corrosion fatigue performance of LPB processed 300M steel with shot peened (SP) and low stress ground (LSG) conditions. They found that the LPB steel produced residual compression to a depth of $1.27 \mathrm{~mm}$, and the SP steel only 0.127 $\mathrm{mm}$. They found that the LPB treatment dramatically improved both the high cycle fatigue performance and corrosion fatigue strength, with and without simulated FOD. They also found that 
the corrosion fatigue strengths of LSG and SP surfaces decreased dramatically, to only $20 \%$ and $50 \%$, respectively of the baseline strength; with no discernible endurance limit behavior under corrosion fatigue conditions. They saw that the fatigue behavior was even worse with FOD simulated with a $0.5 \mathrm{~mm}$ deep notch produced by electrical discharge machining both in air and exposed to salt. In contrast, they found that the LPB treated specimens with FOD exhibited a definite endurance limit of $1035 \mathrm{MPa}$ even under corrosion fatigue conditions. Their SCC testing of LPB treated landing gear sections at 1030-2270MPa static loads was terminated after $1500 \mathrm{hrs}$ without failure, compared to failure in as little as 13 hours without treatment. They observed that, mechanistically; the effect of corrosion and FOD resulted in early crack initiation and growth, thus resulting in dramatic decrease in fatigue performance. They concluded that, despite the existence of similar corrosion conditions; the deep compressive surface residual stresses from LPB treatment mitigated both the individual and synergistic effects of corrosion fatigue and FOD. Moreover, they reported that the deep compressive layer produced by LPB reduced the surface stress well below the SCC threshold for $300 \mathrm{M}$, even under high tensile applied loads, effectively mechanically suppressing the SCC failure mechanism.

Hornbach and Prevey [8] observed that 300M steel is often used in landing gear because of its high strength and high fracture toughness. Conversely, they also observed that $300 \mathrm{M}$ steel is highly susceptible to corrosion fatigue and SCC, which can lead to catastrophic consequences for aircraft landing gear. They also noted that shot peening and plating of the landing gear are used to suppress corrosion fatigue and SCC of the steel with limited success. They reasoned that a method that will produce deeper compression in critical regions of landing gear will provide a dramatic improvement in foreign object damage (FOD) tolerance, corrosion fatigue strength, and SCC susceptibility. In their paper, they discussed the use of low plasticity burnishing (LPB) for providing a deep layer of residual compression to improve damage tolerance and mitigate SCC of $300 \mathrm{M}$ steel. They compared the fatigue performance of LPB processed $300 \mathrm{M}$ steel test samples to those in a shot peened or lowstress-ground (LSG) condition. They reported that the LPB treatment dramatically improved the high cycle fatigue (HCF) and corrosion fatigue performance with and without a simulated defect. They also reported that the LPB reduced the surface stress well below the SCC threshold for 300M, even under high tensile applied loads; effectively suppressing the SCC failure mechanism. SCC testing of LPB treated landing gear sections at tensile stresses ranging from 1030-2270MPa was terminated after $1500 \mathrm{hrs}$ without failure, compared to failure in as little as 13 hours without LPB treatment

SCC behavior of ultra-high strength steel (300M steel) in a $3.5 \% \mathrm{NaCl}$ solution was studied by Sun et al [23] using potentiodynamic polarization and slow strain rate testing (SSRT) techniques. They observed the fracture surfaces of the steel at different applied potentials by scanning electron microscopy (SEM). They attributed the SCC mechanism of the steel in the $\mathrm{NaCl}$ solution at open circuit potential to anodic dissolution. They reported that chloride ions significantly increased the SCC sensitivity of the $300 \mathrm{M}$ steel. They also found that at the anodic applied potential of $-600 \mathrm{mV}$, the anodic dissolution rate and SCC susceptibility of 300M steel increased as represented by loss of its reduction-in-area at open circuit potential with increment from 52.6\% to 99.5\%. In addition, they found that cracks generally initiated at corrosion pits and the SCC mechanism remained anodic dissolution. They found that at the cathodic potential of $-800 \mathrm{mV}$, the $300 \mathrm{M}$ steel exhibited a lower SCC sensitivity due to cathodic protection which maintained its strength and toughness values close to those in air. They concluded that the SCC of the steel was controlled by anodic dissolution and hydrogen induced cracking. By their conclusion, when the applied potential was more negative than $-950 \mathrm{mV}$, the $300 \mathrm{M}$ steel exhibited a higher SCC sensitivity. They finally reported that the SCC mechanism was hydrogen induced cracking due to a synergistic action of stress and hydrogen.

SCC behavior of 30CrMnSiNi2A low alloy ultra-high strength steel of comparable strength to 300M steel was investigated in $3.5 \mathrm{wt} \% \mathrm{NaCl}$ solution by Jianhua et al [(24] using slow strain rate technique (SSRT) with various strain rates and applied potentials, surface analysis technique, and 
electrochemical measurements. They found that SCC susceptibility of the steel increased rapidly with strain rate decrements from $1 \times 10^{-5} \mathrm{~s}^{-1}$ to $5 \times 10^{-7} \mathrm{~s}^{-1}$, and became stable when strain rate was lower than $5 \times 10^{-7} \mathrm{~s}^{-1}$. They indicated that SCC propagation of the steel in the solution at open circuit potential (OCP) needed sufficient hydrogen which was supplied at a certain strain rate. They found that fracture surface at OCP had similar characteristics with that at cathodic polarization of $-1000 \mathrm{mV}_{\mathrm{SCE}}$, which presented characteristic fractography of hydrogen induced cracking (HIC). They found these entire indicative that SCC behavior of the steel in the solution at OCP is mainly controlled by HIC rather than anodic dissolution.

Guma and Ajayi [7] reaffirmed that SCC is the type of corrosion that is highly loathed due to unpredictable attendant disastrous consequences from it. They lamented that $300 \mathrm{M}$ steel is a special but notable failure-prone structural material by SCC. The motive of their study was to find the SCC mitigation extents of $300 \mathrm{M}$ steel by tempering and normalizing heat treatments in seven aqueous media that contained different concentrations of hydrochloric acid $(\mathrm{HCl})$ and sodium chloride $(\mathrm{NaCl})$ as critical corrosive species up to $17.5 \%$. They produced 56 ASTM E-8 standard tensile test samples from procured un-heat-treated $300 \mathrm{M}$ steel for the study. Out of the 56 samples, 28 were not heat-treated, while 14 were heat-treated by tempering and 14 by normalizing. They systematically cleaned all the samples to uniformly smooth surface finishes and each loaded to the same maximum tensile bending stress of $1427.4 \mathrm{MPa}$ by cantilevering. They determined the bending load to induce the stress according to Equation (1) [7].

$$
\sigma=\frac{32 m g l}{\pi d^{3}}
$$

Where; $m$ was mass of the hung load at the free end of the cantilevered sample, $g$ was the acceleration due to gravity $=9.81 \mathrm{~m} / \mathrm{s}^{2}, l$ was $52 \mathrm{~mm}$ (distance of the applied load from the fixed end of the cantilevered specimen), $d$ was the diameter of the gauge length of the cantilevered sample $=5 \mathrm{~mm}, \sigma=1427.4 \mathrm{MPa}$ (the stress applied to each sample under test). With equation (1), they evaluated the hung mass to be $34.36 \mathrm{~kg}$. They tested the loaded samples by immersing them in pairs of one tempered with one un-heat-treated and one normalized with one un-heat-treated in each of the seven prepared aqueous media under separate constant temperatures of $60^{\circ} \mathrm{C}$ and $100^{\circ} \mathrm{C}$ for one hour. After the immersion duration, they removed the samples for integrity evaluation with respect to internal and surface cracks by micro-examination. The results they obtained showed no SCC for all the heat-treated samples but multiple trans-granular crack features alongside craters that increased in intensity with the acid and chloride contents and propagated in the matrix structure to the steel surfaces for the un-heat-treated samples tested at $100^{\circ} \mathrm{C}$ in the media that contained from $14 \% \mathrm{HCl}$ and $14 \% \mathrm{NaCl}$.

\section{Conclusion}

An overview of 300M steel as a special engineering material for fracture toughness and highstrength applications and its drawback as an SCC-prone material has been presented. Merits and demerits of methods of alleviating the SCC problem of the steel have been highlighted for better understanding of the problem for the way forward by concerned engineers and researchers. It has been seen from the overview that SCC-alleviation of the steel has not yet reached ideal level due to some impracticability and cost implications in using the SCC control methods in many cases, and no better alternative material has been found for the steel. Only few research inputs on the numerous environmental types that the steel can be in service contact with are found in the literatures for its SCC alleviation. Improving practicability and versatility of the existing SCC control methods and optimization of SCC-susceptibility test information of the steel from much larger number of the 
environmental types and their various levels of combinations are deemed needful towards ideal SCC alleviation of the steel.

\section{References}

[1] Mayanglambam, R.S., Sharma, V., and Singh, G. (2011). Musa ParadisiacaExtract as a Green Inhibitor for Corrosion of Mild Steel in 0.5M Sulphuric Acid Solution. PortugaliaeElectrochimica Acta, 29(6), pp. 405-417.

[2] Finsgar, M., and Jackson, J. (2014). Application of Corrosion Inhibitors of Steels in Acidic Media for Oil and Gas Industry: A Review. Corrosion Science Vol. 86, pp. 17-41.

[3] Guma, T.N., Atiku, S. A., and Abdullahi, A. A. (2017). Corrosion Management and Control: Entrepreneurial Opportunities and Challenges in Nigeria. International Journal of Engineering Research and Application, 7(10), pp.14-23.

[4] Ramamurthy, S., andAtrens, A. (2013). Stress Corrosion Cracking of High-Strength Steels. De GRUTER Corros Rev, 31(1), pp. 1-31.

[5] Guma, T. N., Ajayi, E. O., and Mohammed, M. H. (2020). Standard Techniques of Stress Corrosion Cracking Testing: A Review. Journal of Newviews in Engineering and Technology (JNET), 2 (1), pp. 58-72.

[6] Guma, T.N., Solomon, W.C., and Sambo, H.L. (2014). Assessment of Stress Corrosion Cracking (SCC) Susceptibilities of Some Outokumpu-Produced Stainless Steels in a River Harbor Mud Using Accelerated Test. International Journal of Engineering Sciences and Research Technology, 3(11), pp. 672-680.

[7] Guma, T.N., and Ajayi, E.O. (2019). Effects of Tempering and Normalizing Heat Treatments on Stress Corrosion Cracking Behaviors of Modified AISI 4340 (300M). Steel in Acidic Chloride Media. Nigerian Research Journal of Engineering and Environmental Sciences, 4(2), pp. 604-616.

[8] Hornbach, D. and Prevéy, P. (2007). Reducing Corrosion Fatigue and SCC Failures in 300M Steel Landing Gear Using Low Plasticity Burnishing, SAE Technical Paper 2007-01- 3838.

[9] Prevéy, P.S., and Jayaraman, N.(2004). Mitigation of SCC and Corrosion Fatigue Failures in 300M Landing Gear Steel using Mechanical Suppression. Lamda Technologies. Proceedings of the 6th Aircraft Corrosion Workshop August 24-27, 2004, Solomons, MD pp 1-12.

[10] Guma, T.N., and Abu J. (2018). A Field Survey of Outdoor Atmospheric Corrosion Rates of Mild Steel around Kaduna Metropolis. SSRG International Journal of Mechanical Engineering. 5 (11), pp. 7 21

[11] Guma,T.N., Aku, S.Y., Yawas, D.S., and Dauda, M. (2014). An Overview Assessment of Various Surveyed Corrosion Protection Approaches for Steel, IORS, Journal of Engineering, 4(11), pp. 48-56.

[12] Guma,T.N., Aku, S.Y., Yawas, D.S., and Dauda, M. (2015). Bitumen in Coating Corrosion Protection of SteelThe Position and Prognosis of Nigerian Bitumen. American Journal of Engineering Research, 4(12), 2015, pp. 101-111.

[13] Guma, T.N., Olayiwola, O., and Garba, D.K. (2019). Effects of Some Heat Treatments on Corrosion of Low and Medium Carbon Steel in Acidic Chloride Medium. World Scientific News, 132, pp. 169-186.

[14] Chen, W., Voisin, T., Zhang, Y., Floren, J., Spadacchi. C.M., McDowell, D.L., Zhu, T., and Wang, Y.M. (2019). Micro-scale residual stresses in additively manufactured stainless steel. Nat Commun 10, 4338.

[15] Nazarova, M.N., Akhmetov, R.R., and Krainov, S.A (2017). Temperature factors effect on occurrence of stress corrosion cracking. IOP Conf. Series: Earth and Environmental Science 87. IOP Publishing

[16] John Pechonick. The effect of cathodic protection on the stress corrosion characteristics of 300M low alloy steel. Master's thesis, University of Missouri Rolla, 1971.

[17] Ryder, J., and Pickel, F. (1978). Effect of Temperature on Stress Corrosion Cracking of 300M Steel, Journal of Testing and Evaluation, 6(2), pp. 129-133.

[18] Padmanabhan, R., and Wood, W.E. (1985). Stress Corrosion Cracking Behavior of 300M Steel under Different HeatTreated Conditions, CORROSION. 41(12), pp. 688-699.

[19] Kerr, R., Solana, F., Bernstein, I.M., and Thompson, A.W. (1987). Micro-structural effects on the stress corrosion cracking behavior of medium and high strength steels. Metallurgical and Materials Transactions A, Volume 18, Issue 6, pp. 1011-1022.

[20] Kozol J., and Neu, C.E. (1992). Stress Corrosion Susceptibility of Ultra-High Strength Steels for Naval Aircraft Applications, Report No. Nawcadwar-92018-60 *Af Ad-A256 126. Naval Air Warfare Center, Aircraft Division Warminster, Pa 18974-5000.

[21]Lee, E.U., and Waldman, J. A. (1994). Corrosion of Aircraft Landing Gear Steels. .https://doi.org/10.1111/j.1559-3584.1994.tb02355.x

[22] Hiten Awasthi (2012). The Effect of Heat-Treating Temperatures on Induced Compressive Residual Stress and Fatigue Life in 300M Landing Gear Steel Due to Shot Peening. A Thesis Presented to Ryerson University in partial fulfillment of the Requirement for the degree of Master of Applied Science in Mechanical Engineering, Toronto, Ontario, Canada. 
T. N. Gumaetal./ NIPES Journal of Science and Technology Research

2(3) 2020 pp. $236-247$

[23] Sun, M., Xiao, K., Dong, C., Li, X., and Zhong, P. (2012). Electrochemical behavior and stress corrosion cracking of 300M ultrahigh strength steel. Journal of University of Science and Technology Beijing, 34(10), pp. 1159-1166.

[24] Jianhua, L., Qiang, G., Mei, Y., andSongmei, L. (2014). SCC investigation of low alloy ultra-high strength steel $30 \mathrm{CrSiNi} 2 \mathrm{~A}$ in $3.5 \mathrm{Wt} \% \mathrm{NaCl}$ solution by slow strain rate technique". Chinese Journal of Aeronautics, 27(5), pp.1327-1333. 